\title{
MEASURING INFORMATION SOCIETIES: A CRITICAL STUDY OF THE INFOSTATE FRAMEWORK
}

\author{
Anouk Mukherjee \\ London School of Economics and Political Science, UK
}

\begin{abstract}
In this chapter, I use critical theory to explore the underlying philosophy of the infostate framework for measuring information societies in developing countries. I find the hallmarks of instrumental reason when examining the framework and argue that this risks giving policymakers a false sense of clarity when shaping poverty reduction policies in developing countries. Given the influence of the infostate framework on the shaping of policy, this could have serious negative consequences for international efforts. I suggest a thorough critical study of a wider set of frameworks used for policymaking. The study could form the basis for the development of alternative frameworks for the measurement of information societies in developing countries.
\end{abstract}

Keywords: Information society indicators, measuring ICT for development, infostate framework, critical theory, instrumental reason

\section{Introduction}

Information and communications technologies (ICT) have come to assume an important role in international efforts to reduce poverty at the beginning of the 21st century. In 2003 and 2005, the United Nations held two world summits on the information society (WSIS) to support the Millennium Development Goals (MDG). These conferences produced a plan of action upon which efforts to close the global "digital divide" could be based. One of the key objectives of the plan is to develop benchmarking and indicators to measure information societies and hence assess progress towards internationally agreed goals. This undertaking is no doubt a major challenge and has revealed deep divisions in the global discourse on ICT and development.

Countless frameworks to measure the global information society have been constructed. Kim and Nolan [9] present them in three broad categories: the economic, the technological, and the information stock approach. A survey of literature suggests that frameworks used in practice are generally based on an economic approach that is focused on the growing information vector in economic activity. In essence, the economic approach sees ICT as powerful tools for productivity growth which drive overall economic growth which in turn contribute 
to the overall well being of society. Advocates of this approach frequently point to the economic success of ICT-rich societies such as the US as evidence for support [17]. This concentration on economic approaches has become an increasing preoccupation for those promoting a broader theoretical treatment of the problem.

Concern over the lack of a unified meta-theory in the measurement of the information society has been voiced for some time $[6,9,10,11,24,25]$. Grigorovici et al. [6] are particularly critical of the self-referential nature of many frameworks used by international organisations. Other critics argue that past approaches have been too fractured and specialised to provide a comprehensive framework for the measurement of the information society $[3,11]$. However, the call for broader theories is being heeded and some very diverse and original frameworks for improved measurement of the global information society have been developed [3, 14, 25]. For instance, Petrič [14] has elaborated a framework based on Habermas' theory of communicative action to measure the use of personal Web sites in Slovenia.

In this chapter I explore the basis for the criticism of the current dominant economic approaches. I critically examine one of the leading economic frameworks and discuss its limitations. By gaining a better understanding of the challenges faced by those developing frameworks, I hope to inform further research into better ways of measuring information societies.

I am guided in my reflection by critical theory, and more specifically the ideas or "fragments" exposed by Theodor Adorno and Max Horkheimer [1]. I specifically chose to explore the thinking behind the infostate framework, which is used to study the link between ICT and development $[18,20]$ and used by the International Telecommunication Union (ITU) for its ICT Opportunity Index. ${ }^{1}$ The application by the ITU gives the infostate framework wider recognition and therefore could have significant influence on policymaking and the development of other frameworks.

I draw from semi-structured guided interviews with experts who construct and use frameworks for the measurement of information societies: the Chief of the ICT Policy and Analysis Section, United Nations Conference on Trade and Development (UNCTAD); Associate Economic Affairs Officer, UNCTAD; Visiting Fellow and creator of the infostate framework, International Development Research Centre (IDRC); and independent telecoms policy consultant, Antelope Consulting.

The rest of the chapter is structured as follows: Section 2 provides a description of the infostate framework and traces its origin and use. Section 3 discusses the biases and limitations of the framework, drawing from a critical theoretical perspective; in particular, my critique highlights the instrumental reasoning underlying the framework and its use and comments on the risks such an approach implies for the cause of development. Finally, in the conclusions I suggest how this research could be taken further.

${ }^{1}$ See: http://www.itu.int/ITU-D/ict/publications/ict-oi/2007/index.html. 


\section{The infostate framework and model}

Orbicom (Network of UNESCO Chairs in Communications) developed the infostate framework in response to the G8 Digital Opportunities Task (DOT) Force Genoa Plan of Action of 2001. The project was sponsored in large part by the Canadian government through the Canadian International Development Agency (CIDA) but also had the backing of the InfoDev Programme of the World Bank [18]. The framework was developed to satisfy the need for "adequate approaches to quantify and monitor ICT-related gaps between info-poor and inforich countries" [17]. The perception was that there were no satisfactory frameworks available for policymakers and a new one needed to be constructed urgently. The infostate framework is aimed at policymakers at all levels of governance - donors, investors, and NGOs - and seeks to guide policymaking or investment choices and also to evaluate the results of these choices over time [18, 20].

The infostate framework is based on the assumption of a very strong link between ICT and development. Evidence for this link is drawn from research on ICT and productivity in developed countries. In the first publication exposing the framework, Sciadas, cites research from 2000 on the US economy by Jorgensen and Stiroh [17] for support. The experts I interviewed confirmed their belief in this strong link as does the latest publication updating the framework: "Concerted efforts have been devoted to the specific issue of untangling the linkages between the diffusion and the use of ICTs and economic development. Almost instinctive early beliefs that ICTs represent a powerful new addition to the development arsenal are increasingly coupled with hard evidence that this is so" [20].

The fundamental belief that ICT can drive growth makes it the focus of the infostate framework. The framework follows a very clear and linear logic based on neo-classical economic theory where the distinction between the consumptive and productive capacity of an economy is crucial. The standard of living - and by extension well-being - of a society depends largely on its current consumption of goods and services. Its well being in the future, however, is ensured by the productive capacity of the economy. Increased well-being therefore can be reached by growth of the productive capacity which also translates to economic development. ICT participates in this development both as a consumptive and productive asset. For example, home broadband would be considered a consumable service and the word processing skills of an office worker a productive asset. An infostate is defined as the level at which ICT is integrated in economic activity as both consumptive and productive assets in a given economy [17].

In order to make this framework operational in practice, an infostate needs to be broken down into measurable entities. Consumptive and productive ICT assets are subdivided into categories that are in turn subdivided repeatedly until an elementary measure is reached. For example, productive ICT assets can be subdivided into two categories - capital and labour. Capital can then further be 
subdivided into networks and machinery. This exercise can be repeated until one arrives to measurable items such as cables, keyboards, and routers. The resulting tree structure represents the model applied for determining the infostate of an economy. The aggregation of indicators makes the infostate a composite index. In this manner, the infostate indicator is similar to the consumer price index (CPI). An infostate can be measureable over time and could allow comparison between countries at a given point in time [17].

In 2001, the model was used to measure the infostate of countries representing 99\% of the world's population. Countries in Western Europe, North America, Australia, New Zealand, Japan, and Singapore had the highest infostate, while Myanmar, Bangladesh, and the poorest nations in Africa scored the lowest. Not surprisingly, the results also showed a strong correlation between infostate and per capita GDP [18].

\section{Critique of the infostate framework}

To begin, the development of such a framework would have to overcome one fundamental problem of measuring information societies. Without rich and appropriate data, understanding the phenomenon is almost like guesswork, while without an appropriate framework, the collection and representation of data is difficult. Menou in 1985 likened this to a "chicken and egg" problem [10] and Grigorovici et al. echoed the analogy in 2002 [6]. In order to overcome this challenge, the infostate framework was designed to be "conducive to empirical application" and to make "maximum sense out of existing data sources" [19].

In practice, such an approach carries the risk of becoming self-referential. The result of the 2001 study ranking countries by infostate finds a strong link between ICT and economic growth. Therefore, according to the publication, the link is confirmed and the framework validated for application. The empirical application of the framework reveals that the underlying assumption is true and the framework is valid.

The assumption of a universal link between ICT and development is questionable. The link in the infostate framework is a static set of relationships between ICT, productivity growth, and human development. Sciadas frequently points to the success of developed nations that have ICT virtually penetrating all economic activity as evidence of this link [17]. In this perspective, the success of nations is judged on the basis of various economic indicators such as GDP, technological infrastructure, and innovation. The nations are then classified accordingly as developed, developing, or least developed. The logic follows a topdown approach where economies at the bottom should emulate those at the top in order to progress and attain the same levels of success. Critics see this as a narrow economic view of development because it disregards evidence that one cannot predict the impact of introducing ICT into a certain social context based on the results in a different social context $[2,4,21]$. Being based on the experience of ICT and economic growth in the West, the infostate framework could be 
overlooking key differentiating factors in developing countries. One of these factors is what Kim and Nolan call the "technoeconomic heritage" of different countries and regions [9]. No consideration for such factors is provided in the elaboration of the infostate framework [17, 19]. In fact, it is founded upon the basic assumption that the laws of society are universal and constant over time. This is despite the fact that Sciadas acknowledges the use of the framework may only be useful when comparing similar economies [17].

Heeks and Kenny state that the assumption of a universal link between ICT and development ignores the failures of information systems in developed nations [7]. There is a significant lack of evidence that ICTs are radically improving the efficiency and effectiveness of organisations. Heeks and Kenny further argue that developed countries would benefit most from the global diffusion of ICT since it embodies Western institutions - or "scripts" [22] - and the production of the technology is dominated by developed nations.

Sciadas believes that ICT presents an "historic" opportunity for the evolution of our societies $[17,20]$. This perception is consistent with the idea that ICT has changed the rules of history and its arrival represents a break from the past. The belief that the classic stages of economic development - the historical path of the West - are no longer valid is widely held by the interviewed experts. They believe developing nations can "leapfrog" the classic stages of development by exploiting the benefits of ICT. They further argue that ICT is changing the rules of international development economics and acknowledge it is an emerging phenomenon. But how can one rely on a framework to measure an emerging phenomenon over time when the foundations of the framework itself are expected to shift?

The context surrounding development of the infostate framework can be a cause of bias. Specifically, the urgency given by politicians to measuring the global information society has favoured those approaches that can deliver results in a speedy and short-term, cost effective manner. This situation can make extensive and thoughtful research into the issue difficult [3]. Furthermore, frameworks based on broader social theory face the danger of not being taken seriously because they are not universally recognised. They therefore risk being rejected by international organisations for practical use in measuring the global information society [11]. In this environment, economic frameworks such as infostate are perceived as having a solid empirical track record in the West and will likely carry favour by policymakers.

This critical reflection on the infostate framework suggests that its development may have been grounded in instrumental reason. Under instrumental reason, moral reason is disconnected from the subjects' aspirations and desires. Each person or living being is considered to be an object of science. These objects are catalogued, standardised, and quantified into an abstract form of reality which can be manipulated for the purposes of science, industry, and utility in general. In order to have the power of prediction over space and time, instrumental reason consists of universal laws that are presumed to be all encompassing. It ignores the 
specificities of context whether geographical or temporal and considers anything that eludes it to be of mythological or superstitious origin. Instrumental reason has come to replace the emancipatory reason of the Enlightenment and has dictated the subservience of human consciousness to economic and political interest. Instrumental reason provides society with a sense of false clarity and always uses "the devices of familiarity and straightforward dismissal to avoid the labour of conceptualization" [1].

The notions of universality, detachment from context, tacit and unfounded assumptions, and praxis - hallmarks of instrumental reason - appear through the lens of critical theory when examining the infostate framework. Universality, detachment from context, and tacit and unfounded assumptions take root in the link between ICT and development used by the framework. Praxis is present in the concurrent development and validation of the framework in a pressurised political environment. These predispositions may be inappropriate grounding for a framework that measures a complex and evolving phenomenon that is intricately linked to the historical path of nations. Consequently, the embedded instrumental reason risks giving policymakers a false sense of clarity when shaping poverty reduction policies in developing countries. This would imply that the infostate framework could misguide international efforts and perhaps even work against the goals of the Millennium Declaration. Such a failure would not only be a major setback for international organisations fighting for global equity, but also a tragedy for those suffering the blight of poverty.

\section{Conclusions}

Although the efforts to measure the information society take root in the highly desirable goal of poverty reduction, as embodied by the MDGs, the philosophical underpinnings of these efforts should be critically examined. This is vital especially given the failures of the past in reducing poverty on the planet.

In this chapter, I have explored the infostate framework that is currently used by the ITU for its influential ICT opportunity index. This preliminary examination suggests that its roots in instrumental reason limit its ability to help in unpacking the complex relationship between ICT, poverty, and development. It is principally handicapped by its unawareness of the wider social, political, cultural, and historical contexts in the measurement of the information society. The solidity of the framework is further undermined by its use to validate the questionable assumption of the strong link between ICT and development - an assumption upon which the framework itself is based.

If these patterns of thinking are confirmed and are shared with other dominant frameworks used to measure the global information society, then questions should be raised about their potential effectiveness. Can such frameworks provide an accurate and meaningful picture to help guide poverty reduction in developing countries? Could they in fact work against the achievement of MDG objectives and reinforce existing disparities? 
These questions could form the basis of a more thorough critical study supported by empirical evidence. It should cover a wide spectrum of frameworks that are in use today to measure the information society in developing countries. From this study, alternative multidisciplinary approaches could be developed in order to provide a broader perspective on the problem at hand.

\section{References}

[1] Adorno, T. W., M. Horkheimer, \& J. Cumming (1997). Dialectic of enlightenment, London: Verso Editions.

[2] Avgerou, C. (2002). Information systems and global diversity, Oxford: Oxford University Press.

[3] Barzilai-Nahon, K. (2006). Gaps and bits: Conceptualizing measurements for digital divides", Information Society, 22(5), 269-278.

[4] Ciborra, C. \& Lanzara, G. F. (1994). Formative contexts and information technology: Understanding the dynamics of innovation in organizations", Accounting, Management and Information Technology, 4(2), 61-86.

[5] Freeman, C. (1997). The "national system of innovation" in historical perspective. In D. Archibugi and J. Michie.(Eds.) (pp. 24-49) Technology, Globalisation and Economic Performance, Cambridge: CUP.

[6] Grigorovici, D. M., Schement, J.R., \& Taylor, R.D. (2002) .Weighing the intangible: Towards a framework for information society indices, E-Business Research Center Working Paper.

[7] Heeks, R. \& Kenny, C. (2002). ICTs and development: Convergence or divergence for developing countries? Proceedings of the 7th International Working Conference of IFIP WG9.4, 29-31 May 2002, Bangalore, India.

[8] Held, D. (1980). Introduction to critical theory: Horkheimer to Habermas, London: Hutchinson.

[9] Kim, S. \& P. D. Nolan (2006). Measuring social "Informatization": A factor analytic approach, Sociological Inquiry, 76 (2), 188-209.

[10] Menou, M. J. (1985). An overview of social measures of information, Journal of the American Society for Information Science, 36 (3), 169-177.

[11] Menou, M. J. \& R. D. Taylor (2006). A "Grand Challenge": Measuring information societies, Information Society, 22(5), 261-267.

[12] Mowshowitz, A. (1980). Ethics and cultural integration in a computerized world, Human Choice and Computers, 2, 251-269.

[13] Mowshowitz, A. (1981). On approaches to the study of social issues in computing, Communications of the ACM, 24 (3), 146-155.

[14] Petrič, G. (2006). Conceptualizing and measuring the social uses of the internet: The case of personal web sites, The Information Society, 22 (5), pp. 291 - 301.

[15] Porter, M.E., Sachs, J.D., Cornelius, P.K., McArthur, J.W., Schwab, K. (2002) The global competitiveness report 2001-2002, New York, Oxford University Press.

[16] Pruulmann-Vengerfeldt, P. (2006) Exploring social theory as a framework for social and cultural measurements of the information society, The Information Society, 22 (5), pp. $303-310$.

[17] Sciadas, G. (2002) Monitoring the digital divide, Orbicom.

[18] Sciadas, G. (2003). Monitoring the digital divide... and beyond, Orbicom. 


\section{Social Dimensions of ICT Policy}

[19] Sciadas, G. (2005). Infostates across countries and over time: Conceptualization, modelling, and measurements of the digital divide, Information Technology for Development, 11 (3), pp. 299-304.

[20] Sciadas, G. (2005). From the digital divide to digital opportunities: Measuring infostates for development, Orbicom.

[21] Suchman, L. (1987). Plans and situated action, Cambridge: Cambridge University Press.

[22] Suchman, M. (1995). Managing legitimacy: Strategic and institutional approaches, The Academy of Management Review, 20 (3), pp. 571-610.

[23] UNCTAD (2006). Information economy report 2006, the development perspective.

[24] van Dijk, J. A. G. M. (2006). Digital divide research, achievements and shortcomings, Poetics, 34 (4-5), pp. 221-235.

[25] Vehovar, V., et al. (2006). Methodological challenges of digital divide measurements, The Information Society, 22 (5), pp. 279 - 290.

[26] WSIS (2003). Building the information society: A global challenge in the new millennium, Geneva Declaration of Principles. 